\title{
Fiber-Forming Properties of Poly(vinyl alcohol) Derived from Poly(vinyl pivalate)
}

\author{
Ryohei Fukae $^{* 1}$, Tohei Yamamoto ${ }^{* 2}$, Yoshitaka Imori ${ }^{* 3}$, \\ Osamu Sangen ${ }^{* 2}$, and Mikiharu Kamachi*-1 \\ * Himeji Junior College. Shinzaikehoncho, Hineji. 670 Japan \\ * ${ }^{2}$ Himeji Institute of Technology, Shosha, Himeji, 671.22 Japan \\ *3 Kawasaki Heavy Industries, Ltd., Akashi, 673 Japan \\ * Faculty of Science. Osaka University, Toyonaka, 560 Japan
}

\begin{abstract}
Fiber-forming properties of poly(vinyl alcohol)s (PVAs) with high syndiotacticities (diad syndiotacticity $=61-65 \%)$ derived from poly(vinyl pivalate) (PVP) were studied. PVA with moderate molecular weight (ca. $7 \times$ $10^{4}$ ), which was derived from PVP, showed a high fiber-formability and provided fibers having a high degree of crystallinity and a high mechanical strength. One the other hand. PV As having fairly high molecular weights $(>4$ $\times 10^{5}$ ) and having high syndiotacticities were less drawable owing to the strong intermolecular forces caused by the stereoregularity.
\end{abstract}

\section{Introduction}

The crystal modulus of poly(vinyl alcohol) (PVA) in the direction parallel to the chain axis is very high. estimated to be from 250 to $300 \mathrm{GPa}$, because the molecular chains in the crystal take a planar zigzag conformation (1). In addition, having a high modulus in the direction perpendicular to the chain axis and a high crystal melt. ing point. PVA can be expected to provide a prominent fiber with high strength and modulus.

Many methods, such as gel-spinning $[2,3]$. solid state. extrusion of single crystal mat [4], zone drawing [5], and use of PVA with high molecular weight, have been applied to obtain PVA fibers with ultra-high strength and modulus. Most PVAs used for these methods were derived from poly(vinyl acetate) (PVAc) and their stereoregularities were low.

We developed a new preparation method of PVA with high syndiotacticity. The process consists of the photoemulsion polymerization of vinyl pivalate (VP) and the exhaustive saponification of obtained poly(vinyl pivalate) (PVP) $[6,7]$. The PVA prepared using this process exhi. bited a higher crystal melting point and a higher mod. ulus in the temperature range above the glass transition than a commercial PVA derived from PVAc [8]. These different characteristics are attributed to an intense in. termolecular force caused by hydroxyl groups with high syndiotactic configurations. Regulation of the intermolecular force is an important factor in order to obtain good fiber-formability by allowing the molecular chains to build up advanced molecular orientation.

At the present stage of the study on stereoregularity of PVA. little is known about the physical properties other than results obtained by Yamaura et al. (9-11] which deals with poly(vinyl trifluoroacetate) (PVTFAc). Stereoregularity of PVA derived from PVP is higher than that derived from PVTFAc. In addition, when using $V P$ as a monomer. PVA with high molecular weight is easily obtained by photo-enulsion polymerization at low temperatures [7]. Thus, PVP makes it possible to provide highly stereoregulated PVA, and the adaptation of the obtained PVA to a fiber manufacturing process is of important significance to the textile industry. Reports on the fiber preparation of PVA having syndiotacticity over $60 \%$ and ultra-high molecular weight have not been published to date. The present investigation was undertaken to observe the fiber-formability of PVA with high syn. diotacticity $(>61 \%$ (diad)) derived from PVP and to ev aluate the fiber properties. 
Table 1 PVA Samples Used for Fiber Preparation

\begin{tabular}{lccc}
\hline $\begin{array}{c}\text { Sample } \\
\text { No. }\end{array}$ & $\begin{array}{c}\text { Degree of } \\
\text { polymerization }\end{array}$ & $\begin{array}{c}\text { Diad syndio- } \\
\text { tacticity (\%) }\end{array}$ & $\begin{array}{c}\text { Degree of } \\
\text { saponification (\%) }\end{array}$ \\
\hline s.PVA(VH) & 12,900 & 62.8 & $>99.9$ \\
s.PVA(H) & 9.000 & 62.8 & $>99.9$ \\
s.PVA(M) & 4.400 & 64.7 & $>99.9$ \\
s.PVA(L) & 1,690 & 61.2 & $>99.9$ \\
s.PVA(VL) & 730 & 64.9 & $>99.9$ \\
\hline a.PVA(L) & 1.750 & 53.9 & $>99.9$ \\
\hline
\end{tabular}

a) Estimated from intrinsic viscosity of acetylated PVA.

\section{Experimental}

\subsection{Preparation of PVA}

PVP was obtained by photo-enulsion and solution polymerization of VP according to the process previously reported by us [7]. Desired PVAs with high syndiotacti. cities (s-PVAs) were prepared by exhaustive saponifica. tion of PVP. Degrees of polymerization $\left(P_{n}\right)$, syndiotacti. cities and degrees of saponification of several PVA sam. ples for the fiber forming process are summarized in Table 1. s.PVA(VH) and s.PVA(H) shown in Table 1 were derived from PVPs which were prepared by the photo emulsion polymerization of $V P$ at $0{ }^{\circ} \mathrm{C} . s$. $P V A(L)$ was derived from PVP which was prepared by solution polymerization of $\mathrm{VP}$ at $60^{\circ} \mathrm{C}$ with $\mathrm{MeOH}$ as a solvent. $s$.PVA(M) and s.PVA(VL) were also derived from PVPs prepared by solution polymerization of $V P$ at $0{ }^{\circ} \mathrm{C}$ with $\mathrm{MeOH}$ a.PVA(L) was a commercially available PVA(Kur. aray $C_{0}$., Ltd.), which was derived from PVAc.

\subsection{Characteristics of PVA Samples}

The $P n$ of PVA was estimated from the intrinsic vis cosity of the acetylated polyners. The degree of syn diotacticity and saponification were determined from the ${ }^{1} H$ NMR spectrum of PVA. 'H NMR spectroscopy was carried out with a JEOL JNM EX.270 using $1 \%$ DMSO- $d_{6}$ solution of PVA.

\subsection{Spinning of PVA Solution}

A DMSO solution of PVA of given concentration was prepared for spinning. The solution was extruded into a MeOH bath held at $0{ }^{\circ} \mathrm{C}$ through a single nozzle having an internal diameter of $0.3 \mathrm{~mm}$ with an air gap of $2 \mathrm{~mm}$. The gel-fiber was rolled up and then kept in an excess amount of MeOH to extract the solvent.

\subsection{Drawing and Annealing}

A two-step drawing process was employed in the pre. sent work. At the first stage of drawing, fibers were drawn at the rate of $130 \%$ or $670 \%$ of original length per minute at $150^{\circ} \mathrm{C}$ in an oven filled with nitrogen gas A second drawing of the above drawn fibers was carried out at the same drawing rates and at various tempera. tures. The drawn fibers were gradually cooled to $100^{\circ} \mathrm{C}$ in the oven while continuing the tension.

\subsection{Birefringence of Fibers}

The birefringence ( $\Delta n$ ) was determined using Eq. 1 with a polarizing microscope Olympus BH-2 with a Berek compensator (12).

$$
\text { (c } 1000) \times 10000 f(t) d=\Delta n \times 10^{3}
$$

where $i=(a+b) \quad 2, c$ is the constant of the compensator $(\mathrm{nm}), a$ is the graduation of the compensator when corres. ponding the top of zero-order stripe to the cross-point of the polarizing microscope, $b$ is the graduation in the reverse direction, $f(i)$ is a constant determined by the $i$ value and $d$ is the diameter of the fiber $(\mu \mathrm{m})$. A mixture of dibutyl phthalate and tricresyl phosphate $(1: 1)$ was used for soaking the samples.

\subsection{Crystallinities of Fibers}

Crystallinities of fibers were estimated from their de. nsities using the assumption that the densities of a fully amorphous sample and a fully crystalline sample of PVA are 1.269 and $1.345 \mathrm{~g} / \mathrm{cm}^{3}$, respectively [13]. The de. nsity was measured at $25^{\circ} \mathrm{C}$ by the floating method in light liquid paraffin-carbon tetrachloride mixture.

\subsection{X-ray Diffraction Analysis}

The wide-angle $X$-ray diffraction patterns were recorded on a flat filn camera with a Rigaku X-ray Dif. 
fractometer, using nickel-filtered $\mathrm{CuK}_{\text {a }}$ radiation $30 \mathrm{kV}$, $20 \mathrm{~mA}$ ). Film were exposed at a distance of $9.5 \mathrm{~mm}$ for

$5 \mathrm{~h}$.

\subsection{Tensile Test}

The tensile tests were carried out at $20{ }^{\circ} \mathrm{C}$ and $65 \%$ $\mathrm{RH}$ on the fibers of $20 \mathrm{~mm}$ gauge length and at a crosshead speed of $20 \mathrm{~mm} / \mathrm{min}$, using a tensile tester, Autograph AG-1000 (Shimadzu Co., Ltd.). The tensile strength and modulus were evaluated from the stressstrain curves.

\subsection{Dynamic Viscoelasticity}

The dynamic storage modulus $E^{\prime}$ and the loss tangent $\delta$ were measured at $110 \mathrm{~Hz}$ and at a heating rate of 3 ${ }^{\circ} \mathrm{C} / \mathrm{min}$ from $-130{ }^{\circ} \mathrm{C}$ using a dynamic viscoelastic DVE.V4 (Rheology Engineering Co., Ltd.).

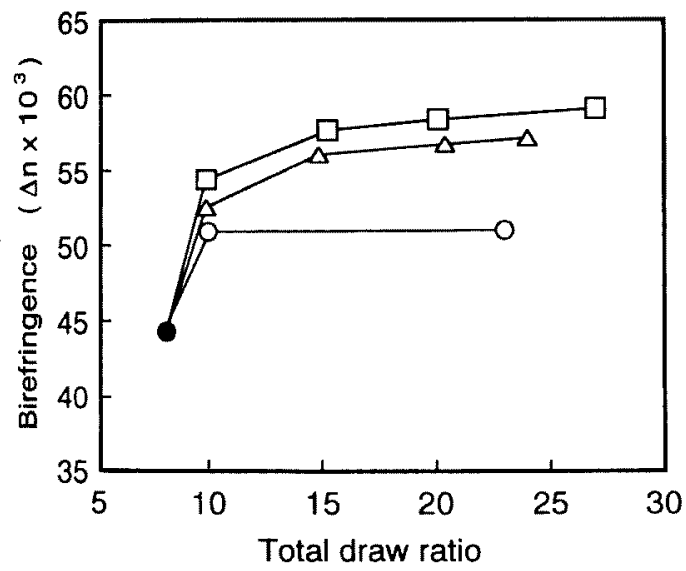

Fig. 1 Changes in birefringence with total draw ratios for s.PVA (L) fibers: 1 st drawing at $150^{\circ} \mathrm{C}: 0.2 \mathrm{nd}$ drawing at $230^{\circ} \mathrm{C}$ after 1 st drawing; $\triangle$. 2nd drawing at $240^{\circ} \mathrm{C} ; \mathrm{L}, 2$ 2nd drawing at $250^{\circ} \mathrm{C}$.

\subsection{Crystal Melting Points of Fibers}

Determination of crystal melting points of fibers was carried out by using a differential scanning calorimeter DSC 8230 (Rigaku Denki Co., Ltd.). The heating rate was $10^{\circ} \mathrm{C} / \mathrm{min}$

\section{Results and Discussion}

\section{$3.1 s$-PVA(L) Fibers}

\subsubsection{Fiber Forming}

Four percent of DMSO solution of $s$-PVA(L) was pre. pared to spin as dilute solution as possible in our spin ning apparatus. In the first drawing at $150^{\circ} \mathrm{C}$. the gel-fi bers stretched maximally to 8 times the original length to exhibit a birefringence value of $44 \times 10^{-3}$. Fibers were then drawn again in the oven at elevated temperatures. i.e., $230^{\circ} \mathrm{C}, 240^{\circ} \mathrm{C}$, and $250^{\circ} \mathrm{C}$. respectively.

Fig, 1 shows the changes in birefringence with the to tal draw ratios in the two-step drawing of fibers. The draw ratio increases with the rise in drawing tempera. ture, and the birefringence of the fiber increases as the draw ratio increases. The efficiency of drawing de. creases as the fiber is stretched to more than 10 times of its original length. In the case of drawing at $250^{\circ} \mathrm{C}$, close to the melting point of s.PVA(L), the fiber can be maximally drawn to 27 times its original length, and the value of the birefringence reaches $60 \times 10^{-3}$. It has been reported (14) that the value of the birefringence of the crystal region of a commercially available PVA derived from PVAc is $51.8 \times 10^{-3}$. The value of the birefringence of PVA, which was derived from PVP in the present work, is higher than that derived from PVAc.

Table 2 Mechanical Properties of s.PVA (L) and a.PVA (L) Fibers ${ }^{\text {a }}$

\begin{tabular}{|c|c|c|c|c|c|c|c|}
\hline \multirow{2}{*}{$\begin{array}{c}\text { PVA } \\
\text { sample }\end{array}$} & \multicolumn{2}{|c|}{ Drawing $^{\text {(b) }}$} & \multirow{2}{*}{$\begin{array}{l}\text { Total } \\
\text { draw } \\
\text { ratio }\end{array}$} & \multirow{2}{*}{$\begin{array}{c}\text { Birefringence } \\
\left(\Delta \mathrm{n} \times 10^{3}\right)\end{array}$} & \multirow{2}{*}{$\begin{array}{c}\text { Crystallinity } \\
(\%)\end{array}$} & \multirow{2}{*}{$\begin{array}{c}\text { Tensile } \\
\text { strength } \\
(\mathrm{GPa})\end{array}$} & \multirow{2}{*}{$\begin{array}{c}\text { Youngs } \\
\text { modulus } \\
\text { (GPa) }\end{array}$} \\
\hline & $\begin{array}{l}1 \mathrm{st} \\
\left({ }^{\circ} \mathrm{C}\right) \\
\end{array}$ & $\begin{array}{l}2 \mathrm{st} \\
\left({ }^{\circ} \mathrm{C}\right)\end{array}$ & & & & & \\
\hline \multirow[t]{4}{*}{$s \cdot \operatorname{PVA}(\mathrm{L})$} & 150 & - & 8 & 14 & 45 & 0.7 & 35 \\
\hline & 150 & 230 & 23 & 51 & 77 & 1.9 & 53 \\
\hline & 150 & 240 & 24 & 57 & 79 & 2.2 & 61 \\
\hline & 150 & 250 & 27 & 59 & 81 & 2.3 & 70 \\
\hline \multirow[t]{2}{*}{$a \cdot \mathrm{PVA}(\mathrm{L})$} & 150 & - & 7 & 38 & 36 & 0.9 & 32 \\
\hline & 150 & 230 & 15 & 45 & 17 & 1.5 & 39 \\
\hline
\end{tabular}

\footnotetext{
${ }^{a)}$ Concentration of PVA in spinning solution: $s$ PVA (L), 4\%; a.PVA (L), 7\%,
}

${ }^{b}$ Drawing rate: $130 \%$ of original length $/ \mathrm{min}$. 


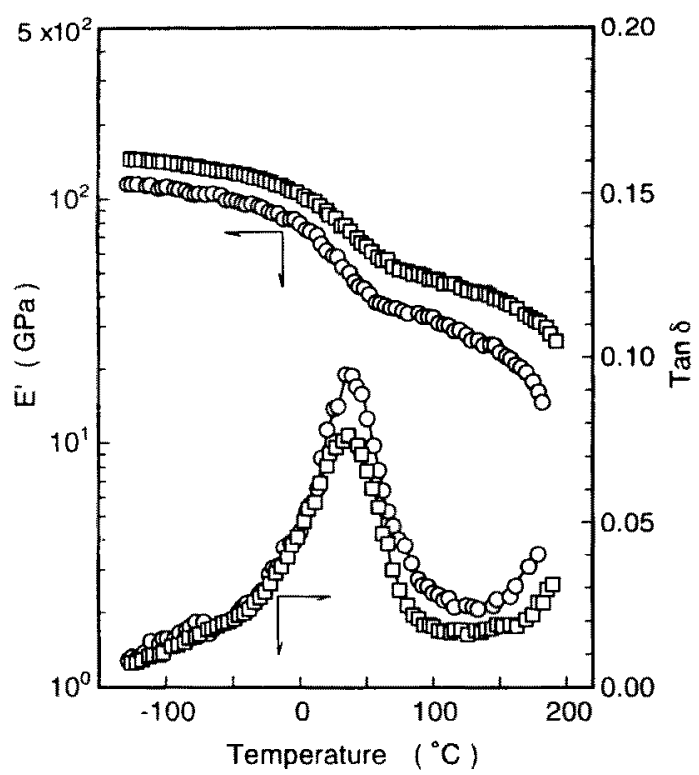

Fig. 2 Temperature dependences of dynamic storage modulus $E^{\prime}$ and tan 0 for PVA fibers: O, a.PVA (L) fiber: $\square$. s.PVA (L) fiber.

\subsubsection{Fiber Properties}

Table 2 shows the properties of $s$-PVA(L) fibers drawn maximally at each drawing temperature. After the second drawing. crystallinity of the fiber fairly increased comparing with that of the fiber treated with first drawing only. The higher the temperature in the second drawing, the higher the crystallinity of the fiber becomes. Specifically, it is noticeable that $s$-PVA(L) fibers drawn at $250^{\circ} \mathrm{C}$ shows crystallinity of $81 \%$. In this case, the ten. sile strength of the fiber is $2.3 \mathrm{GPa}$ and Young's modulus is $70 \mathrm{GPa}$ respectively.

For comparison, the fibers prepared from commercially available PVA, a.PVA(L) were examined, which had approximately the same molecular weight as that of the s.PVA(L). Gel-spinning was done using 7\% DMSO.PVA wolution, and fiber-drawing was carried out at $150^{\circ} \mathrm{C}$ followed by the drawing at an elevated temperature of $230^{\circ} \mathrm{C}$. 5 -P A(L) fibers showed higher crystallinity and more desirable mechanical properties than the a.PVA(L) fibers (Table 2). Fig. 2 shows the temperature depend. ence of dynamic viscoelasticities of $a$.PVA(L) and $s$. PVA(L) fibers. At all tenperatures measured, the storage modulus values for s.PVA(L) were higher than those for a.PVA(L) and the degree of decrease in modulus value of s.PVA(L) with the rise in temperature was smaller than

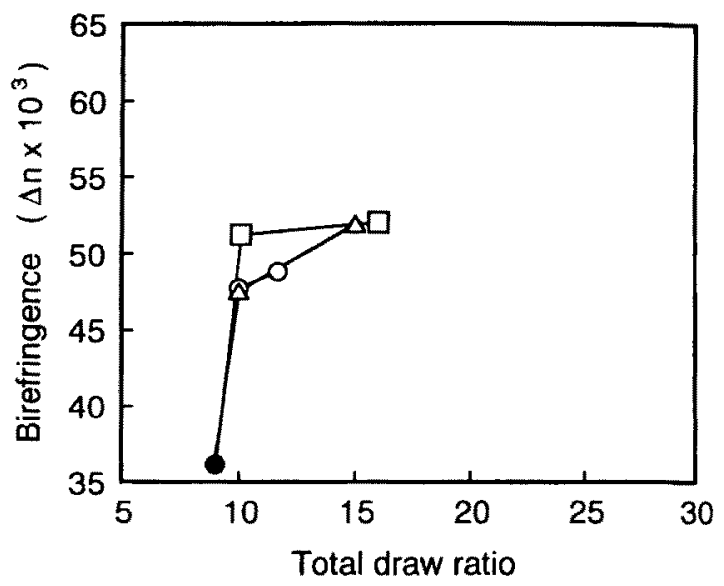

Fig. 3 Changes in birefringence with total draw ratios for s-PVA (VH) fibers: 0 . Ist drawing at $150{ }^{\circ} \mathrm{C} ; \mathrm{O}$. 2nd drawing at $230^{\circ} \mathrm{C}$ after 1 st drawing; $\triangle$, 2nd draw ing at $240{ }^{\circ} \mathrm{C} ; \square .2$ nd drawing at $250{ }^{\circ} \mathrm{C}$

that of a-PVA(L) in the temperature region over the glass transition temperature.

\section{$3.2 s$-PVA(VH) Fibers}

\subsubsection{Fiber Forming}

Enhancing of molecular weight causes the fewer terminal points in the molecular chains and allows the tie molecules to increase, resulting in an enhancement of the fibrous structure $[2,3]$. s.PVA(L) formed a fiber having a higher Young's modulus than that of a.PVA(L) as de. scribed above. Therefore, $\mathrm{PVA}(\mathrm{VH})$ with high syndiotacticity and high molecular weight is considered to form a fiber with more desirable mechanical properties.

s.PVA(VH)-DMSO solution (2.5 wt\%) was used for spinning. The first drawing was carried out at $150^{\circ} \mathrm{C}$. and the second drawings were at various temperatures. As shown in Fig. 3, though s.PVA(VH) fiber is maximal. ly drawn to as the same degree as that of $s$-PVA(L) in the first drawing, the birefringence of the drawn fiber remains low in comparison with the case of $s$-PVA(L).

In the second drawing, the drawing is effective to in. crease birefringence value at every testing temperature at a low drawing ratio. However, the maximum draw ratio is 12 at $230^{\circ} \mathrm{C}$ and the draw ratio and the bire. fringences value are lower at $240{ }^{\circ} \mathrm{C}$ and $250{ }^{\circ} \mathrm{C}$ than those in the cases of $s$-PVA(L) fibers. It is very hard to draw s-PVA(VH) fiber effectively, even though the temperature is close to its crystal melting point.

Fig. 4 shows wide angle X-ray diffraction patterns of 


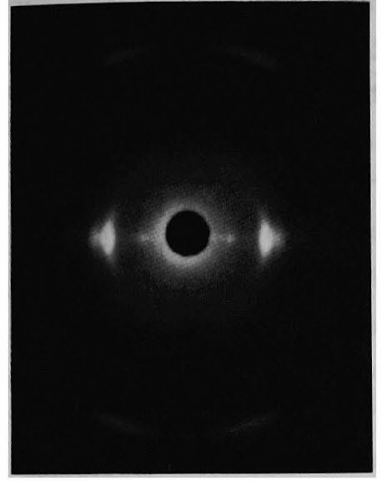

(a)

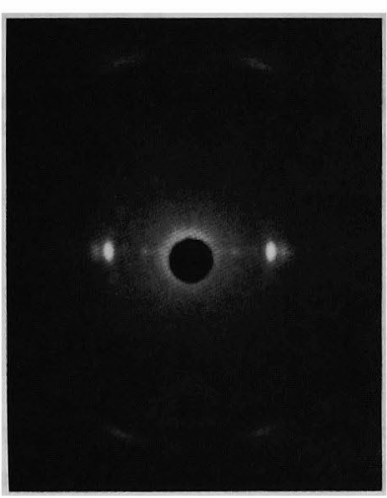

(b)

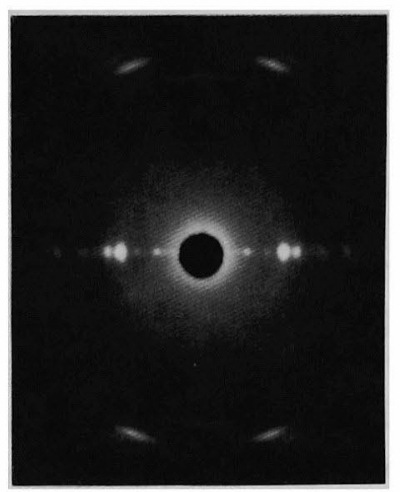

(c)

Fig. 4 Wide angle X-ray diffraction patterns for PVA fibers: (a) $s$-PVA (VH) fiber drawn at $150{ }^{\circ} \mathrm{C}$; (b) $s$-PVA (VH) fiber drawn at $150{ }^{\circ} \mathrm{C}$ (1st drawing) and $250{ }^{\circ} \mathrm{C}$ (2nd drawing); (c) s-PVA (L) fiber drawn at $150{ }^{\circ} \mathrm{C}$ (1st drawing) and $250{ }^{\circ} \mathrm{C}$ (2nd drawing).

Table 3 Mechanical Properties of $s$-PVA (VH) Fibers ${ }^{\text {a) }}$

\begin{tabular}{ccccccc}
\hline \multicolumn{2}{c}{ Drawing } \\
1st & 2st & $\begin{array}{c}\text { Total } \\
\text { draw } \\
\text { ratio }\end{array}$ & $\begin{array}{c}\text { Birefringence } \\
\left(\Delta \mathrm{n} \times 10^{3}\right)\end{array}$ & $\begin{array}{c}\text { Crystallinity } \\
(\%)\end{array}$ & $\begin{array}{c}\text { Tensile } \\
\text { strength } \\
(\mathrm{GPa})\end{array}$ & $\begin{array}{c}\text { Young's } \\
\text { modulus } \\
(\mathrm{GPa})\end{array}$ \\
\hline slow & - & 9 & 36 & 37 & 0.7 & 29 \\
fast & - & 9 & 35 & 32 & 0.7 & 25 \\
slow slow & 16 & 52 & 62 & 1.7 & 49 \\
slow fast & 15 & 45 & 60 & 1.4 & 46 \\
fast slow & 15 & 47 & 58 & 1.1 & 41 \\
\hline
\end{tabular}

${ }^{\text {a) }}$ Concentration of PVA in spinning solution, $2.5 \%$. ${ }^{\text {b) }}$ Drawing: in an oven at $150{ }^{\circ} \mathrm{C}(1 \mathrm{st})$ and $250{ }^{\circ} \mathrm{C}$ (2nd). Drawing rate: slow, $130 \%$ of original length/min; fast, $670 \%$ of original length/min.

s.PVA(VH) fibers. By adding the second drawing, the lattice spots of (100) and (001) planes are located near the equatorial axial line as the crystal can align along the drawing direction. However, the degree of orientation of $s$ - $\mathrm{PVA}(\mathrm{VH})$ fiber is not so high as that of $s$ - $\mathrm{PVA}(\mathrm{L})$ fiber under the drawing condition shown in Fig. 4.

\subsubsection{Fiber Properties}

Fiber properties of $s$-PVA(VH) are listed in Table 3. The birefringence values and degree of crystallinities are low. Also, the tensile strength is $1.7 \mathrm{GPa}$ and Young's modulus is $49 \mathrm{GPa}$ when heat-treatment is done at 150 ${ }^{\circ} \mathrm{C}$ and $250{ }^{\circ} \mathrm{C}$. Though $s$ - PVA(VH) was expected to have advanced mechanical properties, its tensile strength and Young's modulus were somewhat lower than those of $s$ PVA(L). Drawings at various speeds were tried but no clear effects were observed.

\subsection{Effect of Molecular Weight on Fiber Forming of $s$-PVA}

s.PVA fibers having various molecular weights were prepared and examined in order to discuss the effect of molecular weight on fiber forming. These properties are listed in Table 4. s-PVA(H) fibers, which have smaller molecular weight compared to that of $s-\mathrm{PVA}(\mathrm{VH})$, show properties similar to those of $s$-PVA(VH) fibers. The drawing of $s$-PVA(VH) seemed to be insufficient for aligning its molecular chains, due to entanglement by long molecular chains with strong intermolecular forces enhanced by high syndiotacticity. $s$-PVA(M) fibers, which have twice or larger molecular weight compared to that of $s$-PVA(L), showed inferior mechanical properties. As 
Table 4 Mechanical Properties of s-PVA Fibers ${ }^{\text {a) }}$

\begin{tabular}{cccccccc}
\hline $\begin{array}{c}\text { PVA } \\
\text { sample }\end{array}$ & $\begin{array}{c}\text { Degree of } \\
\text { polymerization }\end{array}$ & $\begin{array}{c}\text { Conc. in spinning } \\
\text { solution } \\
(\%)\end{array}$ & $\begin{array}{c}\text { Total } \\
\mathrm{draw} \\
\text { ratio }\end{array}$ & $\begin{array}{c}\text { Birefringence } \\
\left(\mathrm{An}_{\mathrm{n}} \times 10^{3}\right)\end{array}$ & $\begin{array}{c}\text { Crystallinity } \\
(\%)\end{array}$ & $\begin{array}{c}\text { Tensile } \\
\text { strength } \\
\text { (GPa) }\end{array}$ & $\begin{array}{c}\text { Young's } \\
\text { modulus } \\
\text { (GPa) }\end{array}$ \\
\hline s.PVA(VH) & 12,900 & 2.5 & 16 & 52 & 62 & 1.7 & 49 \\
s.PVA(H) & 9,000 & 2.5 & 16 & 54 & 63 & 1.8 & 50 \\
s-PVA(M) & 4,400 & 2.5 & 22 & 51 & 54 & 1.4 & 47 \\
s.PVA(L) & 1,690 & 4.0 & 27 & 59 & 81 & 2.3 & 70 \\
s.PVA (VL) & 730 & 5.7 & 14 & 46 & 57 & 1.1 & 47 \\
\hline
\end{tabular}

${ }^{2}$ Drawing: in an oven at $150{ }^{\circ} \mathrm{C}$ and $250^{\circ} \mathrm{C}$; Drawing rates; $130 \%$ of original length $/ \mathrm{min}$.

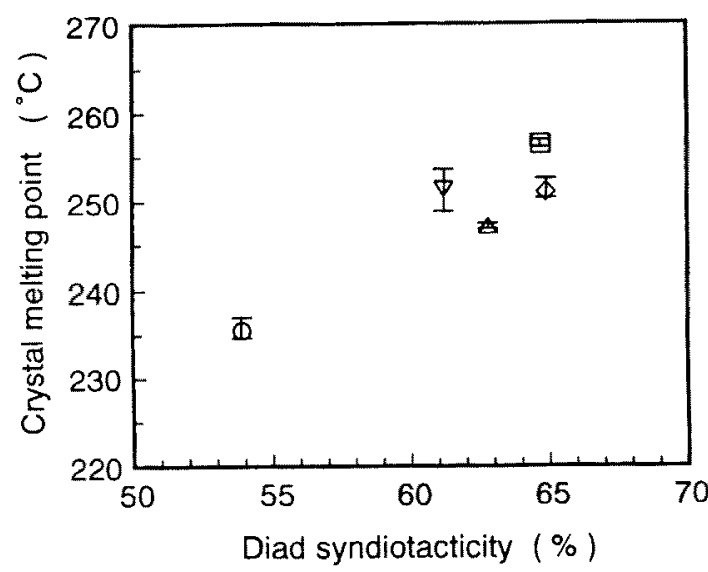

Fig. 5 Crystal melting points of PVA fibers with various tacticities: $O$, a.PVA (L) |crystallinity $(\mathrm{Xc})=47 \%$; $\nabla$ s.PVA (L) $(\mathrm{Xc}=81 \%) ; \triangle$ s.PVA $(\mathrm{VH})(\mathrm{Xc}=62 \%): \square$, s.PVA $(M)(X c=54 \%) ; s$ PVA (VL) $\left(X_{c}=57 \%\right)$.

for the fiber forming of PVA with over $60 \%$ syndiotac. licity, it was found that PVA having a degree of pulynerization of ca 1,700 shows good fiber formability to provide considerable tensile strength properties.

Also. the fiber forming of s.PVA(VL) with a compara. tively low molecular weight was attempted. In spite of a farly low degree of polymerization. it showed a good fiber-forming capability, and yielded a fiber with high crystallinity. 3 -PVA(VL) (xhibited nearly the same liber strength as that of commercial PVA fibers.

\subsection{Crystal Melting Points of $s$-PVA Fibers}

Fig. 5 shows the crystal melting points of fibers pre. pared from s.PVAs. Crystal melting points of $s$-PVAs are 10 C higher than that of a-PVA(L). The tendency for an increase of crystal nielting points with an increase in syndiotacticity was observed. Especially, s-PVA(M) showed a fairly high erystal melting point $\left(256^{\circ} \mathrm{C}\right)$. This suggests the usefulness of $s$-PVA fibers for heat-resistant applications.

\section{Conclusion}

PVA derived from PVP provides a fiber with a high tensile strength and a high Young's modulus. Even when the molecular weight of $s$-PVA derived from PVP was rather low, it was sufficient to provide a good tensile property. The degree of crystallinity of PVA fiber hav. ing a degree of polymerization of 1,700 goes up to $81 \%$. and the fiber shows a tensile strength of $2.3 \mathrm{GPa}$ and a Young's modulus of $70 \mathrm{GPa}$. On the contrary, s.PVA with a fairly high degree of polymerization (12.900) showed a lower fiber formability owing to an entangle. ment of a long chain and a tight intermolecular force caused by the high syndiotacticity.

\section{Acknowledgment}

A part of this research was supported by a Grant-inAid for Scientific Research (No.05650927) from the Ministry of Education. Science and Culture, Japan.

\section{References}

1. K Tashiro, M Kobayashi, and H. Tadokoro, Macro molecules, 11, 914 (1978)

2. Y. D. Kwon, S. Kavesh, and D. C. Prevorsek, U. S. Pat. 4440711 (1985).

3. P. Cebe and D. Grubb, J. Mater. Sci. 20, 4465 (1985).

4. T. Kanemoto. T. Okabe, and H. Sano, Polym. Prepr. Jpm., 35, 1014 (1986).

5. T. Kunugi, T. Kawasumi, and T. Ito, J. Appl. Polym. Sci. $40.2101(1990)$. 
6. T. Yamamoto, S. Yoda, O. Sangen, R. Fukae, and M. Kamachi. Polym. J., 21, 1053 (1989).

7. T. Yamamoto, S. Yoda, H. Takase, T. Saso, O. Sangen, R. Fukae, M. Kamachi, and T. Sato, Polym. J., 23. 185 (1991).

8. R. Fukae, T. Yamamoto, O. Sangen, T. Saso, T. Kako, and M. Kamachi, Polym. J., 22, 636 (1990)

9. K. Yamaura, I. Mizutani, K. Monma, T. Tanigami. and S. Matsuzawa, J. Appl. Polym. Sci., 31, 521 (1986).

10. S. Matsuzawa, L. Sun, and K. Yamaura, Kobunshi
Ronbunshu, 48,691 (1991).

11. K. Yamaura, T. Tanigami, N. Hayashi, K. Kosuda, S. Okuda, Y. Takemura, M. Itoh, and S. Matsuzawa, J. Appl Polym. Sci. 40, 905 (1990).

12. The Society of Fiber Science and Technology Ed., "Sen-i Koubunsi Sokuteiho". Asakura Shoten, Tokyo, p.139(1985)

13. I. Sakurada, T. Nukushina, and Y. Sone, Kobunshi Kagaku, 12, 506 (1955).

14. S. Hibi, M. Maeda, M. Takeuchi, S. Nonura, Y. Shibata, and H. Kawai, Sen'i Gakkaishi, 27. 41(1971). 